\title{
Are boys ready for human papillomavirus vaccine? A national study of
}

\section{boys in Malaysia}

\author{
L.P. Wong ${ }^{1}$, H. Alias ${ }^{1}$, R.N.A.R.M. Yusoff ${ }^{1}$, I-C Sam ${ }^{2}$, G.D. Zimet $^{3}$
}

${ }^{1}$ Centre for Epidemiology and Evidence-Based Practice, Department of Social and Preventive Medicine, Faculty of Medicine, University of Malaya 50603, Kuala Lumpur, Malaysia

${ }^{2}$ Department of Medical Microbiology, Faculty of Medicine, University of Malaya 50603

Kuala Lumpur, Malaysia.

${ }^{3}$ Department of Pediatrics, School of Medicine, Indiana University, 410 W, 10th St., HS 1001, Indianapolis, IN 46202, U.S.

Correspondence: L.P. Wong (Wong Li Ping), Centre for Epidemiology and Evidence-Based Practice, Department of Social and Preventive Medicine, Faculty of Medicine, University of Malaya 50603, Kuala Lumpur, Malaysia. Email: wonglp@um.edu.my, wonglp@ummc.edu.my. +603-79675778

I.C. Sam (I-Ching Sam), Department of Medical Microbiology, Faculty of Medicine, University of Malaya 50603 Kuala Lumpur, Malaysia. Email: jicsam@ummc.edu.my

This is the author's manuscript of the article published in final edited form as:

Wong, L. P., Alias, H., Yusoff, R. N. a. R. M., Sam, I.-C., \& Zimet, G. D. (2019). Are boys ready for human papillomavirus vaccine? A national study of boys in Malaysia. Sexually Transmitted Diseases, Publish Ahead of Print. https://doi.org/10.1097/OLQ.0000000000001024 
G.D.Zimet (Gregory D. Zimet), Department of Paediatrics, School of Medicine, Indiana University, 410 W, 10th St., HS 1001, Indianapolis, IN 46202, U.S. Email: gzimet@iu.edu

Acknowledgements: This study would like to thank the schools and school teachers that were involved in this study.

Conflicts of Interest and Source of Funding: Dr. Zimet has received an honorarium from Sanofi Pasteur for work on the Adolescent Immunization Initiative. For the remaining authors none were declared. This study was supported by the University of Malaya Research Grant (RG411-12HTM).

\section{Short Summary}

A study of boys' intention to receive HPV vaccination found that community intervention is essential to educate parents consenting to HPV vaccination for boys at a young age. 


\section{Abstract}

Background: The aim of this study was to investigate factors associated with the willingness of boys to accept the human papillomavirus (HPV) vaccine.

Methods: A nationwide cross-sectional survey among Secondary One male students in Malaysia.

Results: Among 2823 respondents, knowledge about HPV infection and the HPV vaccine was extremely poor. The mean total knowledge score was only 3.17 ( $\mathrm{SD} \pm 2.14$ ), out of a possible score of 10 . The majority of respondents were unaware that vaccinating boys can help protect girls against HPV infection (81.6\%), and HPV is a sexually transmitted infection (70.1\%). Many had the misconception that only females get HPV (78.9\%). In multivariable analysis, the factors associated with the intention to receive the HPV vaccination were: agreeing boys need to be vaccinated against HPV infection (OR $=2.05,95 \% \mathrm{CI}: 1.57-2.68)$, perceiving their parents might allow them to get the HPV vaccine $(\mathrm{OR}=1.66,95 \% \mathrm{CI}: 1.18-2.34)$, perceived susceptibility to HPV infection $(\mathrm{OR}=1.63,95 \% \mathrm{CI}: 1.06-2.52)$, and attending a rural school $(\mathrm{OR}=1.49,95 \% \mathrm{CI}: 1.14-1.95)$.

Conclusions: Public health educational programs that are focused and tailored on parents consenting to HPV vaccination for boys at a young age can be useful in improving HPV vaccination rates among boys. There is also a pressing need to educate boys about the benefits of HPV vaccination in males and about HPV disease susceptibility to facilitate adoption of the HPV vaccine by young adults in the future.

\section{Keywords}

HPV, HPV vaccination, boys 


\section{Introduction}

HPV, being the most common sexually transmitted infection, is well known for its association with various cancers affecting women including cervical, vaginal, and vulval cancers ${ }^{1,2}$. However, HPV is also associated with male cancers of the penis, anus and oropharynx ${ }^{2}$. The benefit of the HPV vaccine in boys has been understressed as the initial focus and marketing of the HPV vaccine targeted prevention of cervical cancer among women ${ }^{3}$. The National Health and Nutrition Examination Survey (NHANES) 2013 - 2014 reported that the overall genital HPV infection prevalence among 1868 men was $45.2 \%$. Although the clinical benefits of vaccinating boys have been clearly demonstrated ${ }^{5}$, one of the most debated issues is the cost effectiveness of universal vaccination. In 2011, it was reported that including boys in a vaccination programme is especially advisable if vaccine coverage of girls is low ${ }^{6 .}$ However, even in countries with high female coverage there are advantages to vaccinating males. For example, gender-neutral vaccination protects men who have sex with men (MSM) who may not benefit from the herd protection provided by a female-only program. High prevalence of penile and anal HPV infection among teenage $\mathrm{MSM}^{7}$, and in addition to HPV vaccine hesitancy associated to same-sex behavior stigma ${ }^{8}$ further imply the importance of universal HPV vaccine coverage of boys. Also, the goal of cervical cancer elimination, endorsed by the World Health Organization, can be achieved more quickly when high rates of vaccination of both males and females can be achieved ${ }^{9}$. Therefore, the extension of HPV vaccination to boys is anticipated to become more generally recommendedin the near future, particularly when there is low vaccination coverage in women. Vaccinating boys and girls against HPV infection may put Malaysia on the path towards achieving the elimination of cervical cancer. 
In 2009, the quadrivalent HPV vaccine (4vHPV; Gardasil) was licensed in the USA by the FDA for males aged 9 through $26^{6}$. In 2011, the US Advisory Committee on Immunisation Practices recommended routine use of 4vHPV for boys aged 11-12 years, with routine catchup vaccination through age $21^{6}$. For males, 4 vHPV and the more recently licensed 9-valent vaccine $(9 \mathrm{vHPV})$ are approved for prevention of genital warts and anal cancers and precancers. To date, public HPV vaccine programs are now including males in many countries including Canada $^{10}$, Austria ${ }^{11}$, and Austalia ${ }^{12}$.

U.S. studies indicate that HPV vaccine uptake in boys continues to lag behind female vaccination rates, despite the CDC's recommendations and the demonstrated efficacy of the vaccine $^{6,13}$. Therefore, understanding how to promote the HPV vaccination of boys is a public health priority. The Health Belief Model (HBM) is a useful theoretical construct to understand the influence of behaviors related to HPV vaccine uptake. This model is based on the assumption that individuals facing a particular diseases or threat evaluate their susceptibility to the problem and its severity, and then base their decision to take action on the perceived benefits and barriers of different actions ${ }^{14,15}$. Previous studies have shown that perceived severity ${ }^{16}$ and perceived susceptibility of HPV infection ${ }^{17}$ had a positive effect on the intention to obtain an HPV vaccination. Additionally, previous studies also found that adolescent males with less HPV knowledge had higher levels of shame and were less likely to engage in preventive health behaviours, including HPV vaccination ${ }^{18,19}$.

The 4vHPV has also been approved and recommended for males in Malaysia. However, in Malaysia, studies on HPV vaccine acceptability have focused on women and relatively few have focused on men or boys. There was one small scale study that surveyed both boys and girls in rural areas of a state in Malaysia. This study found that there were no significant differences between boys and girls in willingness to be vaccinated against HPV infection ${ }^{20}$. 
Large-scale study on HPV vaccine uptake rates and willingness to receive the HPV vaccine specifically in boys have never been conducted in Malaysia. The Malaysian government has implemented the National HPV immunization programme since 2010, supplying HPV vaccine free to all Secondary One (13 year old) female students including in rural areas at no charge, upon getting parental consent; however, boys are not included in this program. The HPV immunization program in Malaysia has been widely accepted since it was introduced, with more than $95 \%$ participation among female students each year ${ }^{21}$. During the data collection period of this study, the HPV vaccine has not been recommended for boys. Since the HPV vaccine is approved by the FDA for the use in males in year 2018, the HPV vaccine is now available for boys in Malaysia. We have previously surveyed Secondary One female students about their level of knowledge and attitudes to HPV vaccination (findings have been submitted for publication). In this study, we report findings of our survey of male students about their knowledge, health beliefs about HPV infection and vaccinaton, and the factors associated with their willingness to accept the HPV vaccine.

\section{Materials and Methods}

\section{Study participants}

Simple random sampling was used to select 2 secondary schools (each from urban and rural) from all the 13 states and 3 federal territories in Malaysia, giving a total of 32 schools where the nationwide survey was conducted. All Secondary One Malaysian male students in the sampled schools were approached to participate. The paper-based questionnaire was administered to the students between February 2013 and April 2013 in their classroom guided by teachers and research assistants. 


\section{Instruments}

A standardized questionnaire was given to each student. The questionnaire assessed demographic characteristics, and knowledge and health beliefs related to HPV infection and vaccination. In the knowledge section, respondents were asked a series of questions regarding HPV infection, its relationship to cervical cancer and genital warts, HPV vaccine and the effectiveness of the HPV vaccine (10 item scales). Response options were 'true', 'false' and 'don't know'. A correct response was given a score of 1, and an incorrect or 'don't know' was scored as 0 . The possible total knowledge score ranged from 0 to 10 , with higher scores representing higher levels of knowledge.

The second section of the questionnaire assessed respondents' health beliefs regarding HPV vaccination, using the HBM constructs as a theoretical framework ${ }^{16}$. Questions included general heath beliefs (2 items), perceived benefits of HPV vaccine (1 item), perceived susceptibility to HPV (1 item), concerns about getting infected with HPV (1 item) and perceived severity of HPV infection (1 item). Response options were 'agree', 'don't know' and 'disagree'.

The third section of the questionnaire assessed the attitude of respondents towards HPV vaccination (7 items). Seven statements were presented, with response options of 'agree', 'don't know' and 'disagree'.

The questionnaire was in 3 languages: Bahasa Malaysia (Malay), Chinese and English, and was pretested before commencing the study. At each selected school, a survey administrator was appointed and briefed on how to correctly administer the survey questionnaires. 


\section{Pretesting and validation of study instruments}

The questionnaire was content validated by 3 panel experts to ensure the relevance and clarity of the questions. After minor amendments, the questionnaire was pilot tested on 20 randomly sampled students who were not included in the main study. Pilot test participants were included from the 3 main ethnic groups, Malays, Chinese and Indians. The questionnaire was revised again based on student comprehension. Subsequently, the questionnaire was construct validated on 150 randomly selected students and factor loading was calculated to indicate the level of each specific knowledge item. The internal consistency (Cronbach's alpha) of the score for knowledge items was found to be 0.755 . After 2 weeks, test-retest reliability was assessed on a subsample of 80 of the same participants, and found to be $0.3-0.6$, with most kappa values $>0.1$. Based on the outcome of the construct validity and test-retest assessments, the questionnaire was revised again before the start of the actual study.

\section{Ethical considerations}

This study was approved by the Medical Ethics Committee at the University of Malaya Medical Centre, Kuala Lumpur, Malaysia and the Ministry of Education, Malaysia (reference: number 968.3). Written permission was obtained from the State Education Department in each of the states and federal territories in Malaysia. Written permission was also obtained from the principals of the selected schools. Students were informed that their participation was voluntary. Students who agreed to answer the survey questions were asked to sign an informed consent form. All responses were collected and analyzed without identifiers. 


\section{Statistical analysis}

All statistical analyses were performed with Statistical Package for the Social Sciences, version 20.0 (IBM Corp., Armonk, NY, USA). The significance level was set at $p<0.05$. Mean values with standard deviations (SD) or medians with interquartile ranges (IQR) were calculated for continuous variables, while frequencies were counted for categorical variables. Multivariable logistic regression analysis of factors involved in intention to take HPV vaccination was performed. All variables found to have a statistically significant association (two-tailed $p$-value $<0.05$ ) with intention to take HPV vaccination in the univariate analyses were included in the logistic-regression model.

\section{Results}

\section{Characteristics of participants}

A summary of the characteristics of the respondents is provided in Table 1. A total of 2823 responses were received, a response rate of $83.0 \%$. There were no significant differences in response rate by states and urban-rural localities. Most of the respondents were Malay (63.3\%), followed by Chinese $(23.4 \%)$ and Indian $(4.8 \%)$, which is similar to the national distribution of ethnicities. More than half of the participants were Muslims (66.2\%), followed by Buddhists (19.6\%), Christians (8.3\%), Hindus (3.9\%), and Taoists (1.7\%). A total of $73.6 \%$ reported being moderately religious, while $22.7 \%$ were very religious, and $3.7 \%$ were not religious at all. The majority of respondents' mothers were housewives $(61.8 \%)$, while the majority of their fathers were employed as managers (39.5\%) and skilled workers (37.9\%). Slightly over half of the respondents (54.9\%) were from households with a monthly income below MYR 2000 (USD 450). The majority of the schools were located in an urban setting $(63.9 \%)$. 


\section{Source of HPV or HPV vaccination information}

Slightly over half of participants had never heard of HPV or HPV vaccination $(n=1614$, $57.2 \%$ ). As shown in Table 1, a significantly higher proportion of participants with mothers in professional occupations (56.4\%) reported having heard of HPV or HPV vaccination than those with mothers in other occupations. Likewise, a significantly higher proportion of participants with fathers in professional occupations (48.2\%) also reported having heard of HPV or HPV vaccination than those with fathers in other occupations; although, participants with fathers who were unemployed showed the highest proportion $(50.6 \%)$ of those who had heard of HPV vaccination. Participants from schools in urban areas (44.7\%) were significantly more likely to have heard of HPV or HPV vaccination compared to those from rural areas $(39.5 \%)$

Among those who had heard of HPV or HPV vaccination, the most common sources of information were TV or radio (46.9\%) and their teacher (43.7\%). Other sources in order were: newspaper or magazine $(30.6 \%)$, doctor $(20.8 \%)$, peers $(20.0 \%)$ and the internet $(16.5 \%$; Figure 1).

\section{Knowledge about HPV or HPV vaccination}

Figure 2 shows the proportion of correct responses on knowledge items among participants who had heard of HPV or HPV vaccination. Only 2 knowledge items were correctly answered by over half of the respondents, namely vaccines are available to prevent HPV infection (58.1\%) and HPV infection could be asymptomatic (56.2\%). Only $21.1 \%$ knew that males could also get HPV infection. An even lower proportion was aware that vaccinating boys could protect girls against HPV infection (18.4\%) and that HPV could not be cured (17.8\%). 
The mean total knowledge score was $3.17(\mathrm{SD} \pm 2.14)$ out of a possible score of 10 . The median was 3 (inter quartile range, IQR, 1 - 5).

\section{Health beliefs regarding HPV and HPV vaccination}

Approximately half (49.6\%) of respondents believed that the HPV vaccine is good for one's health just like all other vaccines, and $55.6 \%$ believed that taking the HPV vaccine is a good idea as it is recommended by the government. Nearly two-thirds of respondents $(60.7 \%)$ believed that the HPV vaccination is beneficial. Only $9.3 \%$ of respondents felt that they were susceptible to getting infected with HPV. Only $39.9 \%$ were worried about getting infected with HPV and $43.6 \%$ had the belief that infection with HPV can lead to serious illness.

\section{Attitudes towards HPV vaccination}

Table 3 represents respondents' attitudes towards HPV vaccination. A total of $40.1 \%$ agreed with the statement, boys do not need to be vaccinated, only girls should receive the HPV vaccine. A minority (15.6\%) believed that the HPV vaccine is not safe. Only $16.8 \%$ thought that $H P V$ vaccine will not prevent HPV infection. A small proportion agreed with the statements that HPV vaccines may encourage people to have sex at an early age (12.0\%), encourage people to have multiple sexual partners (11.2\%), and my parents might not allow me to get the HPV vaccine (15.4\%). Only $8.6 \%$ noted my religion prohibits me from receiving the HPV vaccine because it is sex-related. Further analysis showed that there were no significant differences in the response across religions. 


\section{Intention to receive HPV vaccination}

In total, less than half $(48.4 \%, \mathrm{n}=1366)$ reported that they were likely to receive the HPV vaccination. As shown in Table 4, variables that were significantly associated with an intention to receive HPV vaccination in the univariate analysis were age, ethnicity, religion, location of school, perceived benefit, perceived susceptibility, perception that boys need HPV vaccine, and parental prohibition to vaccination. From the multivariable logistic regression model, the only 4 significant predictors of intention to receive HPV vaccination were rural location of school $(\mathrm{OR}=1.49,95 \% \mathrm{CI}: 1.14-1.95)$, higher perceived susceptibility to HPV $(\mathrm{OR}=1.63,95 \% \mathrm{CI}: 1.06-2.52)$, perception that boys need $\mathrm{HPV}$ vaccine $(\mathrm{OR}=2.05,95 \%$ CI: $1.57-2.68)$, and the perception that their parents would allow them to get the HPV vaccine $(\mathrm{OR}=1.66,95 \% \mathrm{CI}: 1.18-2.34)$

\section{Discussion}

This nationwide cross-sectional survey recruited samples of students with diverse backgrounds. The finding that a higher proportion of boys whose parents work in professional occupations reported having heard of HPV or HPV vaccination, implies a need to tailor education intervention to lower occupational groups. The low mean knowledge score indicates that the level of knowledge about HPV and HPV vaccination among boys in this study was inadequate. Clearly, such knowledge deficits need to be addressed. While it is important that the current HPV vaccination program in Malaysia focuses on reducing the incidence of cervical cancer among women by giving the HPV vaccine to girls, boys should not be neglected. Briefings about HPV and the HPV vaccine given along with the HPV vaccination to the girls by the healthcare team should be extended to include boys to enable 
them to take precautionary measures against HPV infection and better equip them to make decisions regarding vaccination in the future ${ }^{22}$. Ideally, education tailored for male students should be introduced in schools, communicating to them that HPV infection and diseases are issues for both males and females. Although males are not included in the HPV vaccination program, they can still get the vaccine from private health care providers. Nevertheless, cost would be the major barrier to the uptake of the HPV vaccine in private settings. Currently, the 3-dose HPV vaccines would cost about RM600 to RM700 (USD140 to USD160) if obtained in private clinics in Malaysia. Subsidizing the costs for vaccination would likely raise HPV vaccine uptake among the boys.

The study found that the preceived susceptibility to HPV infection among boys was extremely low. Such a viewpoint potentially threatens adolescent boys' sexual health, as it potentially promotes a neglect of prevention behaviors. As a result, to promote HPV prevention, the high risk of HPV infection among sexually active young adults should be emphasized to adolescent boys in the future. Furthermore, the low perceived severity of HPV infection found in this study also requires attention. Mass media in Malaysia have framed their promotion of HPV vaccine for cervical cancer prevention, but have lacked focus with regard to the consequences of HPV infection in men. The public, especially men, need to know that male HPV infection is an important concern, both for the disease burden in men and for the risk of transmission to women. The general population should understand that HPV infections in men are also associated with a variety of cancers, including anal, penile and oral. The fact that the incidence of anal and oral cancers related to HPV is increasing in the general population worldwide ${ }^{23,24}$ should be made known to the public along with publicity for HPV vaccination of males in Malaysia. 
Another important finding that needs attention was the erroneous belief that boys do not need to be vaccinated, and that only girls should receive the HPV vaccine. The HPV vaccine should not be promoted purely for prevention of cervical cancer among women but also to prevent consequences of HPV infection on men. The current implementation age of HPV vaccination in Malaysia is for 13 year old Secondary One girls, given according to a 3-dose protocol. The program has been very successful, having achieved $98 \%$ coverage $^{25}$. Although including boys in a vaccination programme is thought to be a lower priority with high coverage among girls ${ }^{6}$, communication with patients should highlight the benefits of HPV vaccination to boys in terms of preventing HPV-related diseases among males. In addition, the ultimate goal of cervical cancer elimination can be achieved more quickly with a genderneutral vaccination policy.

Multivariable analysis showed that intention to receive the HPV vaccination was influenced by preceived parental approval for vaccination. Therefore, educating parents in the community at large about vaccinating middle school boys against HPV infection is essential. In addition, the attitudes of health care providers towards recommending the HPV vaccine for males is important ${ }^{26}$. Our previous study revealed a physician's recommendation as the key factor that influenced parents as to the vaccination of their sons aged $11-18$ years old ${ }^{27}$. Perceived susceptibility in the HBM can be used as a framework to guide design for enhancing HPV vaccine uptake among males in Malayisa as it is found to be significantly associated with intention to receive the HPV vaccine in this study. In a recent study, perceived susceptibility was also found to be significantly associated with HPV vaccine uptake among men who have sex with $\operatorname{men}^{28}$. It has been noted that men were not motivated to get vaccinated when they lacked a sense of vulnerability or susceptibility to HPV infection ${ }^{26,28}$. Multivariable anlysis also showed that boys from rural schools were significantly more likely 
to express an intention to receive the HPV vaccine. The reason for the urban-rural disparity in intention to receive the HPV vaccine is unknown. Such findings warrant further investigation, as an understanding of the disparity will help in designing targeted HPV vaccination policies for rural and urban children.

An important implication from this study is the that the strategies to improve HPV vaccine uptake should include emphasizing educating the parents in the community about the importance of HPV vaccination in boys and the high prevalence of HPV in all sexually active adolescents. Of note, although evidence supporting the efficacy of educational intervention in promoting HPV vaccine uptake is lacking ${ }^{29,30}$ there is sufficient evidence suggesting that educational interventions improve the general public's knowledge about HPV and cervical cancer $^{31}$, intention to receive the HPV vaccination and their ability to make informed decisions $^{29,32}$. Therefore, in addition to imparting education, it is also imporant to promote vaccine uptake such as provision of financial subsidies for HPV vaccination of boys.

The limitations of the study are that only Secondary One boys averaging 13 years of age were surveyed, and data collection was cross-sectional and based on self-reporting of data. Of note willingness to receive the vaccine does not necessarily result in receiving the vaccine. Although an individual may be willing to receive HPV vaccine, there are several factors that may prevent them from doing so, such as cost or logistic barriers, that are not investigated in this study. Further investigation of these factors in future studies is warranted. Despite these limitations the sample was large and extended to all states of Malaysia, covering urban-rural locality, thus offering good generalizability. The distribution of average household income in this study closely represent to income distribution of general population in Malaysia in the year of data collection further strengthen the national representativeness of the data. 
This study underscores the need for educational interventions to enhance the HPV vaccinerelated knowledge among boys to highlight the advantages of HPV vaccination for males. While adolescent boys may recognize that HPV causes cervical cancer in women, the severity of HPV infection in men and the benefits of HPV vaccination for males, including prevention of HPV infection in females, are relatively less-known and should be the target of educational intervention. To promote HPV vaccination in males, educational programming targeting males should address health beliefs and emphasize susceptibility to infection. Public health educational programs should also be focused on parents who must consent to HPV vaccination for boys at a young age. 


\section{References}

1. Forman D, de Martel C, Lacey CJ, Soerjomataram I, Lortet-Tieulent J, Bruni L, Vignat J, Ferlay J, Bray F, Plummer M, Franceschi S. Global burden of human papillomavirus and related diseases. Vaccine. 2012 Nov 20;30:F12-23.

2. CDC. Centers for Disease Control and Prevention. What is HPV? Available at: https://www.cdc.gov/hpv/parents/whatishpv.html. 2016. Accessed 9 July 2018.

3. Daley EM, Vamos CA, Zimet GD, et al. The feminization of HPV: reversing gender biases in US human papillomavirus vaccine policy. American journal of public health. $2016 ; 106(6): 983$

4. Han JJ, Beltran TH, Song JW, Klaric J, Choi YS. Prevalence of Genital Human Papillomavirus Infection and Human Papillomavirus Vaccination Rates Among US Adult Men: National Health and Nutrition Examination Survey (NHANES) 20132014. JAMA Oncol. 2017 Jun 1;3(6):810-816.

5. Masterson L, O'Mahony J, Lechner M. Expanding the benefits of HPV vaccination to boys and men. The Lancet. 2016 Dec 17;388(10063):2992.

6. CDC. Centers for Disease Control and Prevention. Recommendations on the use of quadrivalent human papillomavirus vaccine in males: Advisory Committee on Immunization Practices (ACIP), 2011. MMWR Morb Mortal Wkly Rep. 2011;60(50):1705-1708.

7. Zou H, Tabrizi SN, Grulich AE, Hocking JS, Bradshaw CS, Cornall AM, Morrow A, Prestage G, Law MG, Garland SM, Chen MY. Site-specific human papillomavirus 
infection in adolescent men who have sex with men (HYPER): an observational cohort study. The Lancet Infectious Diseases. 2015 Jan 1;15(1):65-73.

8. Zou H, Grulich AE, Cornall AM, Tabrizi SN, Garland SM, Prestage G, Bradshaw CS, Hocking JS, Morrow A, Fairley CK, Chen MY. How very young men who have sex with men view vaccination against human papillomavirus. Vaccine. 2014 Jun 30;32(31):3936-41.

9. Baussano I, Bray F. Modelling cervical cancer elimination. The Lancet. Public health. 2018. doi: 10.1016/S2468-2667(18)30189-0.

10. Quinn S, Goldman RD. Human papillomavirus vaccination for boys. Canadian Family Physician. 2015 Jan 1;61(1):43-6.

11. Orlandi L. Austria to vaccinate boys and girls against HPV [press release] (2013 Sept 18) [cited 2019 Apr 17]. Available from http://www.west-info.eu/austria-tovaccinate-boys-and-girls-against-hpv/

12. Brotherton JM, Batchelor MR, Bradley MO, et al. Interim estimates of male human papillomavirus vaccination coverage in the school-based program in Australia. Comm Dis Intell. 2015 Jun 30;39(2):E197-200.

13. Giuliano AR, Palefsky JM, Goldstone S, et al. Efficacy of quadrivalent HPV vaccine against HPV Infection and disease in males. New England Journal of Medicine. 2011;364(5):401-11.

14. Janz NK, Becker MH. The health belief model: A decade later. Health education quarterly. 1984 Mar;11(1):1-47. 
15. Simon K, Das A. An Application of the Health Belief Model toward educational diagnosis for VD education. Health Educ Quarterly 1984. 4:403-18; http://dx.doi.org/10.1177/109019818401100402

16. Cox DS, Cox AD, Sturm L, et al. Behavioral interventions to increase HPV vaccination acceptability among mothers of young girls. Health Psychology. 2010;29(1):29.

17. Marlow LA, Waller J, Wardle J. The impact of human papillomavirus information on perceived risk of cervical cancer. Cancer Epidemiology and Prevention Biomarkers. 2009;18(2):373-6.

18. Das BC, Hussain S, Nasare V, et al .Prospects and prejudices of human papillomavirus vaccines in India. Vaccine. 2010;26:2669-2679

19. Dorell C, Yankey D, Strasser S. Parent-reported reasons for nonreceipt of recommended adolescent vaccinations, National Immunization Survey—Teen, 2009. Clinical pediatrics. 2011;50(12):1116-24.

20. Jalani FF, Rani MD, Isahak I, et al. Knowledge, Attitude and Practice of Human Papillomavirus (HPV) Vaccination among Secondary School Students in Rural Areas of Negeri Sembilan, Malaysia. International journal of collaborative research on internal medicine \& public health. 2016;8(6):56.

21. Buang SN, Rohani J. Access to new vaccination: the HPV vaccination in Malaysia. First Health Policy Decision Makers Forum Asia Pacific. Singapore. 2012 
22. Krawczyk A, Stephenson E, Perez S, et al. Deconstructing human papillomavirus (HPV) knowledge: objective and perceived knowledge in males' intentions to receive the HPV vaccine. American Journal of Health Education. 2013;44(1):26-31.

23. Johnson LG, Madeleine MM, Newcomer LM, et al. Anal cancer incidence and survival: the surveillance, epidemiology, and end results experience, 1973-2000. Cancer. 2004;101:281-288.

24. Jo S, Juhasz A, Zhang K, et al. Human papillomavirus infection as a prognostic factor in oropharyngeal squamous cell carcinomas treated in a prospective phase II clinical trial. Anticancer Res. 2009;29:1467-1474.

25. LaMontagne DS, Bloem PJN, Brotherton JML, et al. Progress in HPV vaccination in low-and lower-middle-income countries. Int J Gynaecol Obstet. 2017;138(1):7-14.

26. Liddon N, Hood J, Wynn BA, et al. Acceptability of human papillomavirus vaccine for males: a review of the literature. Journal of Adolescent Health. 2010;46(2):113-23.

27. Wong LP, Edib Z, Alias H, et al. A study of physicians' experiences with recommending HPV vaccines to adolescent boys. Journal of Obstetrics and Gynaecology. 2017 Oct 3;37(7):937-43.

28. Lau JT, Wang Z, Kim JH, et al. Acceptability of HPV vaccines and associations with perceptions related to HPV and HPV vaccines among men who have sex with men in Hong Kong. PLoS One. 2013;8(2):e57204.

29. Walling EB, Benzoni N, Dornfeld J, et al. Interventions to improve HPV vaccine uptake: a systematic review. Pediatrics. 2016 Jul 1;138(1):e20153863. 
30. Fu LY, Bonhomme L-A, Cooper SC, et al. Educational interventions to increase HPV vaccination acceptance: A systematic review. Vaccine. 2014 Apr 7;32:1901-1920.

31. Sossauer G, Zbinden M, Tebeu PM, et al. Impact of an educational intervention on women's knowledge and acceptability of human papillomavirus self-sampling: a randomized controlled trial in Cameroon. PloS one. 2014 Oct 15;9(10):e109788.

32. Marlow LA, Wardle J, Forster AS, Waller J. Ethnic differences in human papillomavirus awareness and vaccine acceptability. J Epidemiol Community Health. 2009 Dec 1;63(12):1010-5. 


\section{List of figures}

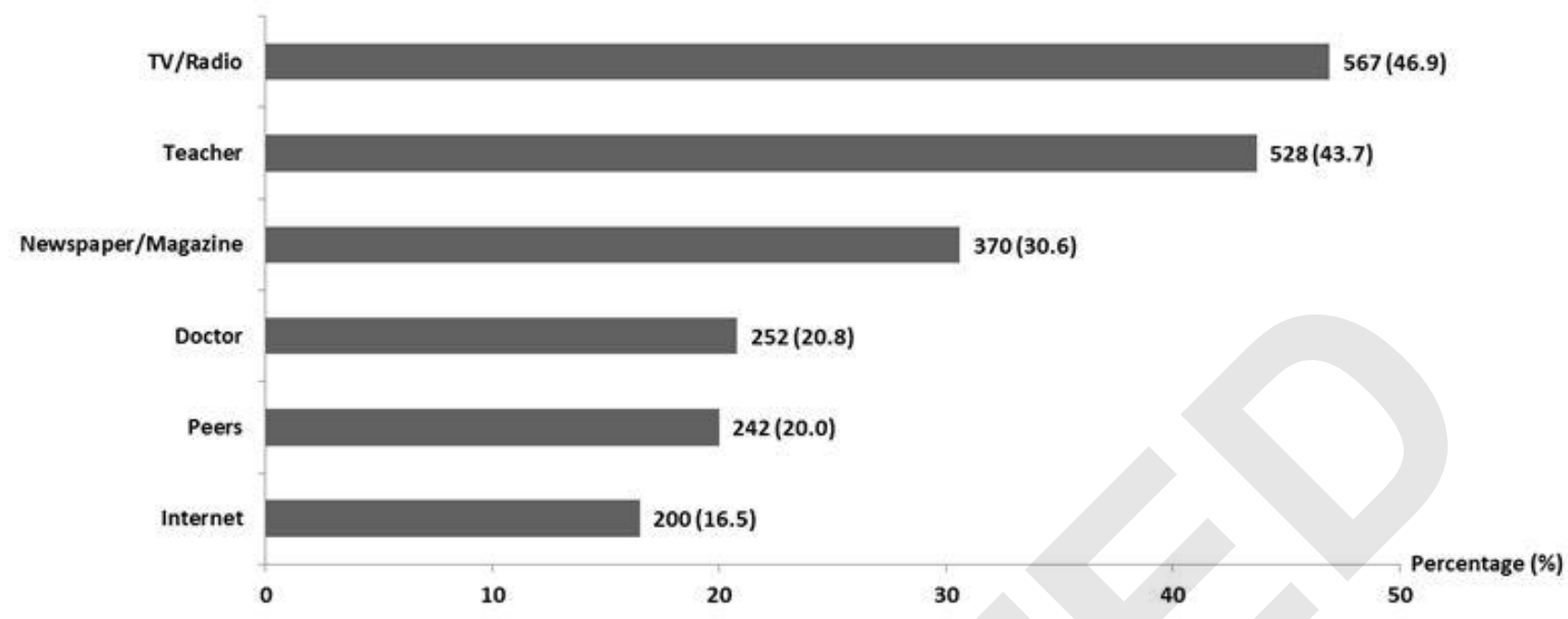

Figure 1 Source of HPV and HPV vaccination information $(\mathrm{N}=1209)$ 


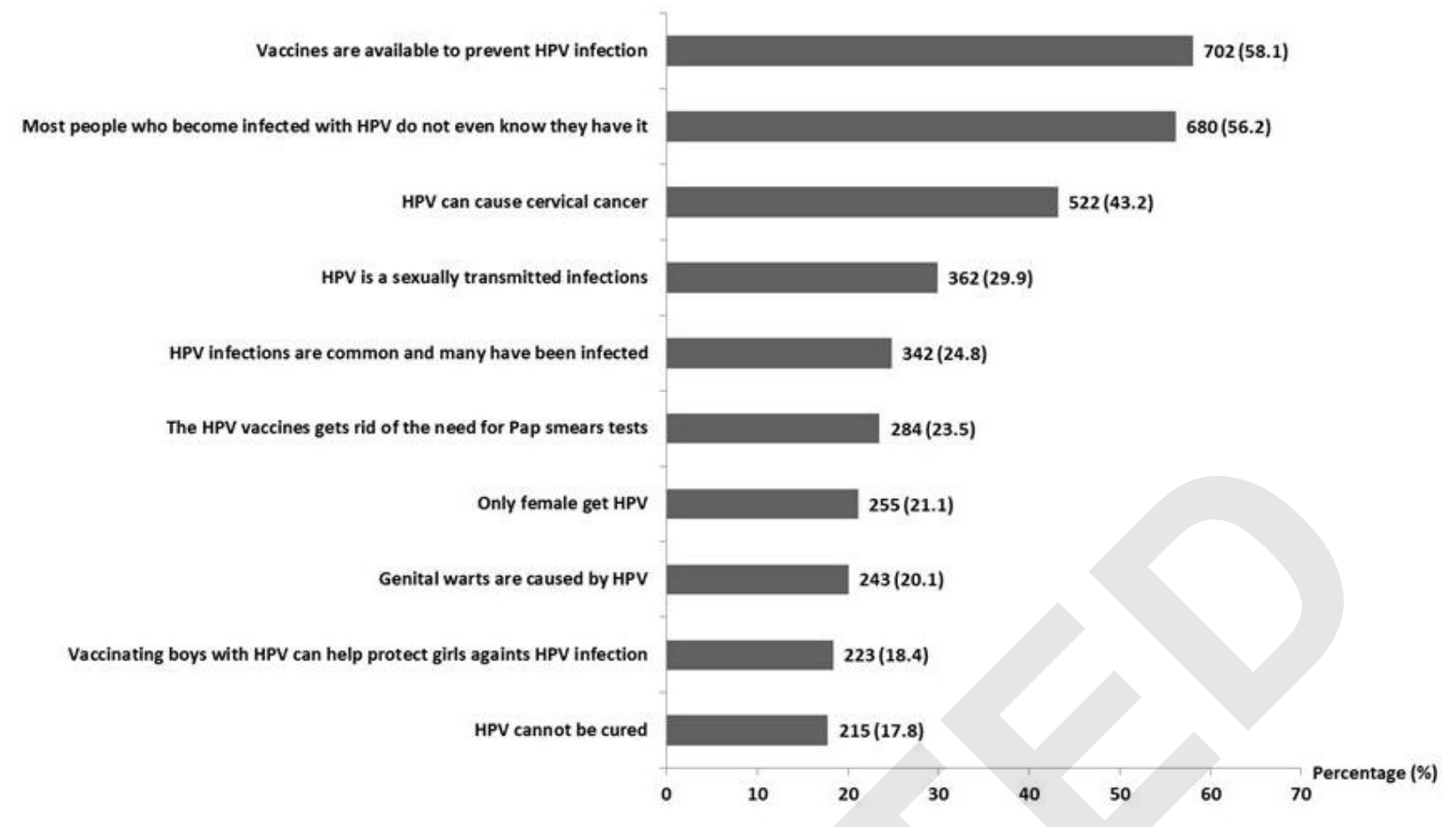

Figure 2 Correct responses on knowledge items $(\mathrm{N}=1209)$ 
Table 1 Distribution of sociodemographic characteristics of the respondents $(n=2823)$

\begin{tabular}{llll}
\hline Overall & Heard of HPV or HPV $\chi^{2}$ \\
& $\mathrm{~N}(\%)$ & vaccination? & $p$-value \\
\cline { 3 - 4 } & Yes & No & \\
& $(\mathrm{n}=1209) \quad(\mathrm{n}=1614)$ & \\
\hline
\end{tabular}

Sociodemographic characteristics

Age (years old)

13

14

Ethnicity

Malay

Chinese

Indian

Aborigines

Others

Religion

Islam

Buddhism

Taoism

Hinduism

Christianity

Others

Religious status

Very religious
$2699(95.6) \quad 1182(43.8) \quad 1517(56.2) \quad p<0.000$

$124(4.4) \quad 27(21.8) \quad 97(78.2)$

$1788(63.3) \quad 857(47.9) \quad 931(52.1)$

$661(23.4) \quad 182(27.5) \quad 479(72.5) \quad p<0.000$

$131(4.6) \quad 58(44.3) \quad 73(55.7)$

$211(7.5) \quad 103(48.8) \quad 108(51.2)$

$32(1.1) \quad 9(28.1) \quad 23(71.9)$

$1869(66.2) \quad 911(48.7) \quad 958(51.3)$

$552(19.6) \quad 149(27.0) \quad 403(73.0)$

$49(1.7) \quad 18(36.7) \quad 31(63.3) \quad p<0.000$

$109(3.9) \quad 50(45.9) \quad 59(54.1)$

$234(8.3) \quad 79(33.8) \quad 155(66.2)$

$10(0.4) \quad 2(20.0) \quad 8(80.0)$

$632(22.7) \quad 291(46.0) \quad 341(54.0)$

24 
Moderately religious

Not at all religious

Mother's Occupation *

Professional

Managerial

Skilled worker

Housewife

Father's occupation *

Professional

Managerial

Skilled worker

Unemployed

Monthly average household income

$$
(\mathrm{MYR})^{*}
$$$$
\leq 1000
$$

$1001-2000$

$2001-3000$

$3001-4000$

$>4000$

Location of school

Urban

Rural
$2046(73.6) \quad 862(42.1) \quad 1184(57.9) \quad 0.102$

$103(3.7) \quad 38(36.9) \quad 65(63.1)$

$342(12.8) \quad 193(56.4) \quad 149(43.6)$

$466(17.5) \quad 194(41.6) \quad 272(58.4) \quad p<0.000$

$217(8.0) \quad 96(44.2) \quad 121(55.8)$

$1657(61.8) \quad 692(41.8) \quad 965(58.2)$

$488(19.4) \quad 235(48.2) \quad 253(51.8)$

$992(39.5) \quad 434(43.8) \quad 558(56.2) \quad 0.028$

$950(37.9) \quad 386(40.6) \quad 564(59.4)$

$79(3.1) \quad 40(50.6) \quad 39(49.4)$

$\begin{array}{llll}858(31.9) & 369(43.0) & 489(57.0) & \\ 617(23.0) & 261(42.3) & 356(57.7) & \\ 407(15.1) & 182(44.7) & 225(55.3) & 0.355 \\ 319(11.9) & 134(42.0) & 185(58.0) & \\ 486(18.1) & 232(47.7) & 254(52.3) & \end{array}$

$1805(63.9) \quad 807(44.7) \quad 998(55.3) \quad 0.007$

$1018(36.1) \quad 402(39.5) \quad 616(60.5)$

Number less than total number of respondents due to lower response rate 
Table 2. Health beliefs regarding HPV and HPV vaccination.

\begin{tabular}{lllll}
\hline Health belief & $\mathrm{n}^{\dagger}$ & Agree & Disagree & Don't know \\
\hline General health belief & & $\mathrm{n}(\%)$ & $\mathrm{n}(\%)$ & $\mathrm{n}(\%)$ \\
\hline HPV vaccine is good for health like other & 1181 & $586(49.6)$ & $128(10.8)$ & $467(39.5)$ \\
vaccines & & & & \\
Taking the HPV vaccine is a good idea & 1179 & $656(55.6)$ & $119(10.1)$ & $404(34.3)$ \\
because it is recommended by the & & & & \\
government
\end{tabular}

\section{Perceived benefit}

$\begin{array}{lllll}\text { The HPV vaccine would be a good way } & 1182 & 717(60.7) & 80(6.8) & 385(32.6)\end{array}$ to prevent HPV infection

\section{Perceived susceptibility}

Do you think you will get infected with $1183 \quad 110(9.3) \quad 326(27.6) \quad 747(63.1)$
HPV?

\section{Feeling of worry}

\begin{tabular}{lllll}
\hline I am worry about getting infected with & 1182 & $472(39.9)$ & $268(22.7)$ & $442(37.4)$
\end{tabular} HPV

\section{Perceived severity}

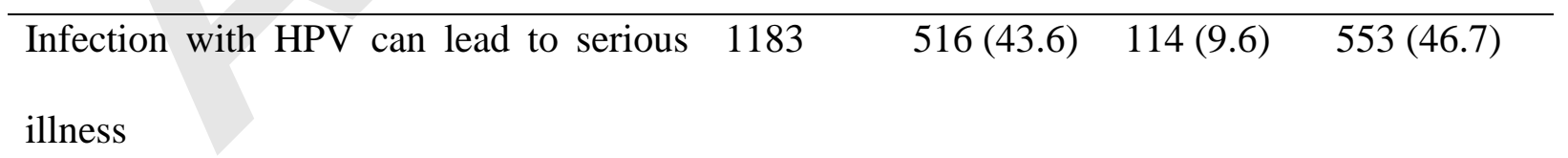

\section{Perceived barriers}

Getting vaccines is scary and painful $\quad 1183 \quad 259(21.9) \quad 307(26.0) \quad 617(52.2)$

\footnotetext{
${ }^{\dagger}$ Number of respondents less than 1,209 (total respondents) due to non-response
} 
Table 3 Attitudes regarding HPV vacccination

\begin{tabular}{lllll}
\hline Attitude & $\mathrm{n}$ & Agree & Disagree & Don't know \\
\hline & & $\mathrm{n}(\%)$ & $\mathrm{n}(\%)$ & $\mathrm{n}(\%)$
\end{tabular}

\section{Attitudes}

Boys do not need to be vaccinated, only $1181 \quad 474(40.1) \quad 200(16.9) \quad 507$ (42.9)

girls should receive the vaccine

The HPV vaccine is not safe for me

$1180 \quad 184(15.6) \quad 346(29.3) \quad 650(55.1)$

I don't think the HPV vaccine will $1175 \quad 197(16.8) \quad 423(36.0) \quad 555(47.2)$

prevent HPV infection

The HPV vaccine may encourage 1179

$142(12.0) \quad 337(28.6) \quad 700(59.4)$

peeople to have sex at an early age

The HPV vaccine may encourage people 1177

$132(11.2) \quad 343(29.1) \quad 702(59.6)$

to have multiple sexual partners

My parents might not allow me to get the 1180

$184(15.6) \quad 280(23.7) \quad 716(60.7)$

HPV vaccine

My religion prohibits me from receiving

1180

$101(8.6) \quad 373(31.6) \quad 706(59.8)$

the HPV vaccine because it is sex-related 
Table 4 Multivariable logistic regression analysis of factors involved in intention to receive HPV vaccination.

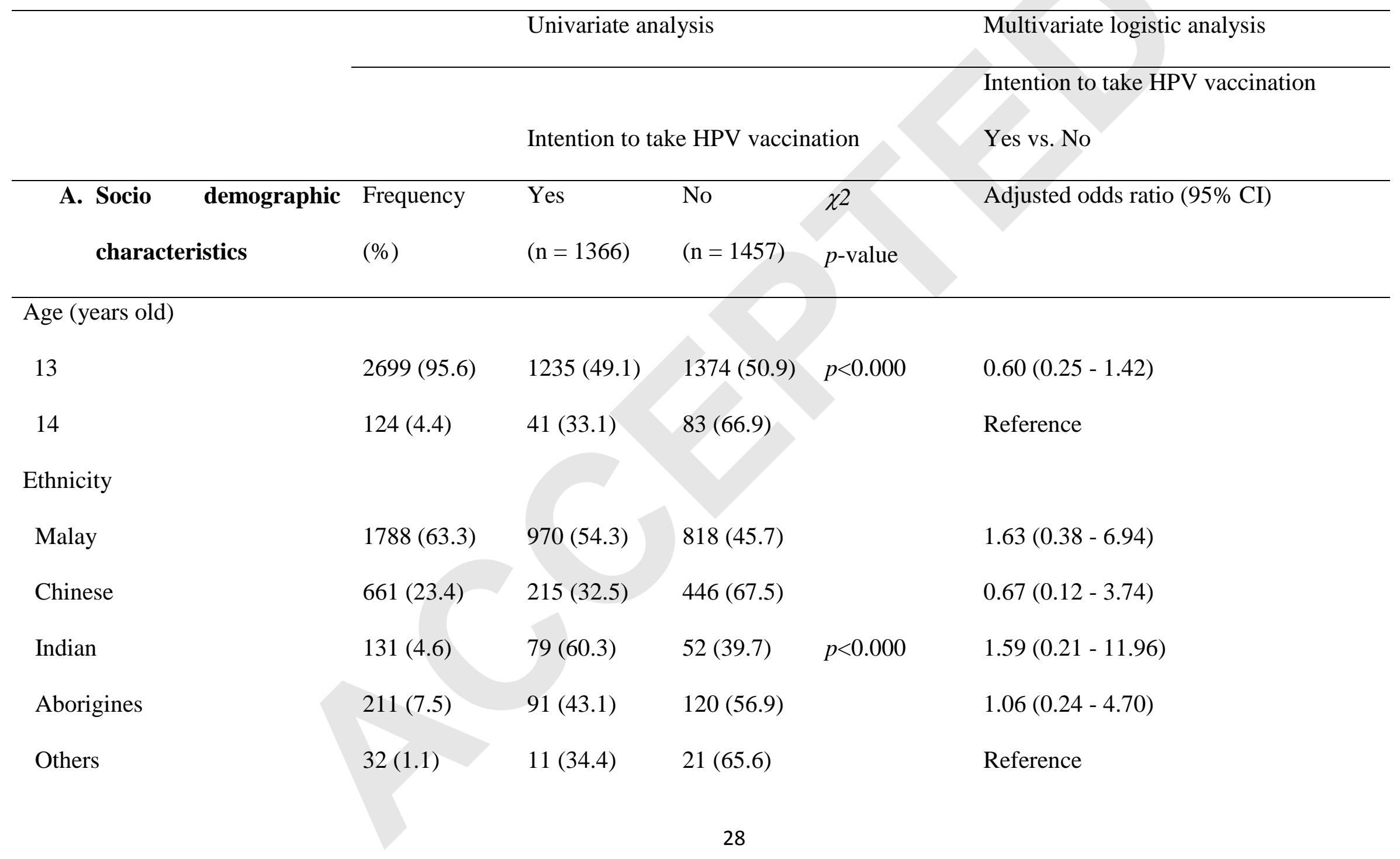


Religion

$\begin{array}{llllr}\text { Islam } & 1869(66.2) & 1009(54.0) & 860(46.0) & 0.98(0.47-2.04) \\ \text { Buddhism } & 552(19.6) & 178(32.2) & 374(67.8) & 0.881(0.35-2.20) \\ \text { Taoism } & 49(1.7) & 15(30.6) & 34(69.4) & 0.000 \\ \text { Hinduism } & 109(3.9) & 68(62.4) & 41(37.6) & 0.61(0.17-2.17) \\ \text { Christianity } & 234(8.3) & 90(38.5) & 144(61.5) & 1.57(0.35-6.98) \\ \text { Others }{ }^{\dagger} & 10(0.4) & 6(60.0) & 4(40.0) & \text { Reference }\end{array}$

Religious status ( $\mathrm{n}=2781$ )

$\begin{array}{lcccc}\text { Very religious } & 632(22.7) & 319(50.5) & 313(49.5) & \\ \text { Moderately religious } & 2046(73.6) & 969(47.4) & 1077(52.6) & 0.376 \\ \text { Not at all religious } & 103(3.7) & 51(49.5) & 52(50.5) & \\ \text { Mother's Occupation }(\mathrm{n}=2682) & 342(12.8) & & & \\ \text { Professional } & 466(17.4) & 169(49.4) & 173(50.6) & \\ \text { Managerial } & 466(16.5) & 232(49.8) & 234(50.2) & 0.510 \\ \text { Skilled worker } & 217(8.1) & 110(50.7) & 107(49.3) & \\ & & & & \end{array}$


Housewife

Father's occupation $(\mathrm{n}=2509)$

Professional

Managerial

Skilled worker

Unemployed

Monthly average household

income (MYR; $\mathrm{n}=2687$ )

$\leq 1000$

$1001-2000$

$2001-3000$

$3001-4000$

$>4000$

Location of school

Urban
$1657(61.8) \quad 777(46.9) \quad 880(53.1)$

$\begin{array}{llll}488(19.4) & 242(49.6) & 246(50.4) & \\ 992(39.5) & 475(47.9) & 517(52.1) & 0.829 \\ 950(37.9) & 449(47.3) & 501(52.7) & \\ 79(3.1) & 36(45.6) & 43(54.4)\end{array}$

$79(3.1)-36(45.6) \quad 43(54.4)$

$\begin{array}{llll}858(31.9) & 414(48.3) & 444(51.7) & \\ 617(23.0) & 306(49.6) & 311(50.4) & \\ 407(15.1) & 202(49.6) & 205(50.4) & 0.808 \\ 319(11.9) & 151(47.3) & 168(52.7) & \\ 486(18.1) & 225(46.3) & 261(53.7) & \end{array}$

$1805(63.9) \quad 839(46.5) \quad 966(53.5) \quad$ Reference 

Rural
$1018(36.1)$
$527(51.8)$
$491(48.2)$
0.008
$1.49(1.14-1.95)^{* *}$

\section{B. HPV knowledge}

Total HPV knowledge score (n

=1209)

$\begin{array}{lllll}0-3 & 658(42.2) & 381(57.9) & 277(42.1) & 0.953\end{array}$

$\begin{array}{lll}4-10 & 551(57.8) \quad 318(57.7) \quad 233(42.3)\end{array}$

C. Health belief

\section{General health belief}

HPV vaccine is good for health just like all other vaccine $(\mathrm{n}=$ 1181)

\begin{tabular}{|c|c|c|c|}
\hline Agree & $586(49.6)$ & $337(57.5)$ & $249(42.5)$ \\
\hline Disagree/ Don’t know & $595(50.4)$ & $344(57.8)$ & $251(42.2)$ \\
\hline
\end{tabular}

Taking the HPV vaccine is a 
good idea because it is

recommended by the

government $(\mathrm{n}=1179)$

\begin{tabular}{|c|c|c|c|}
\hline Agree & $656(55.6)$ & $379(57.8)$ & $277(42.2)$ \\
\hline Disagree/ Don't know & $523(44.4)$ & $303(57.9)$ & $220(42.1)$ \\
\hline
\end{tabular}

\section{Perceived benefit}

The HPV vaccine would be a

good way to prevent HPV

infection $(\mathrm{n}=1182)$

$\begin{array}{llllll}\text { Agree } & 717(60.7) & 393(54.8) & 324(45.2) & 0.016 & 0.91(0.70-1.18) \\ \text { Disagree/ Don't know } & 465(39.3) & 288(61.9) & 177(38.1) & \text { Reference }\end{array}$

\section{Perceived susceptibility}

Do you think you will get

infected with HPV? $(\mathrm{n}=1183)$

\begin{tabular}{|c|c|c|c|}
\hline Agree & $110(9.3)$ & $74(67.3)$ & $36(32.7)$ \\
\hline
\end{tabular}




\begin{tabular}{lllll} 
Disagree/ Don't know & $1073(90.7)$ & $608(56.7)$ & $465(43.3)$ & Reference \\
\hline Feeling of worry & & & & \\
\hline I am worry about getting & & & & \\
infected with HPV $(\mathrm{n}=1182)$ & & & & \\
Agree & $472(39.9)$ & $276(58.5)$ & $196(41.5)$ & 0.674 \\
Disagree & $710(60.1)$ & $406(57.2)$ & $304(42.8)$ & \\
\hline
\end{tabular}

\section{Perceived severity}

Infection with HPV can lead to

serious illness $(\mathrm{n}=1183)$

$\begin{array}{lllll}\text { Agree } & 516(43.6) & 298(57.8) & 218(42.2) & 0.953 \\ \text { Disagree/ Don't know } & 667(56.4) & 384(57.6) & 283(42.4) & \end{array}$

\section{Perceived barriers}

Getting vaccines are scary and

painful $(\mathrm{n}=1183)$

Agree

$259(21.9) \quad 141(54.4) \quad 118(45.6) \quad 0.255$




\begin{tabular}{ll} 
Disagree/ Don’t know $\quad 924(78.1)$ & $541(58.5) \quad 383(41.5)$ \\
\hline Attitudes &
\end{tabular}

Boys do not need to be

vaccinated, only girls should

receive the vaccine $(\mathrm{n}=1181)$

$\begin{array}{llllll}\text { Agree } & 474(40.1) & 227(47.9) & 247(52.1) & 0.000 & \text { Reference } \\ \text { Disagree/ Don't know } & 707(59.9) & 454(64.2) & 253(35.8) & 2.05(1.57-2.68)^{* * *}\end{array}$

HPV vaccines is not safe for me

$(\mathrm{n}=1180)$

$\begin{array}{lllll}\text { Agree } & 184(15.6) & 99(53.8) & 85(46.2) & 0.256 \\ \text { Disagree/ Don't know } & 996(84.4) & 582(58.4) & 414(41.6)\end{array}$

I dont think HPV vaccine will prevent HPV infection $(\mathrm{n}=$ 1175)

Agree

$$
197(16.8) \quad 115(58.4) \quad 82(41.6) \quad 0.753
$$


HPV vaccine may encourage peeople to have sex at an early $\operatorname{age}(\mathrm{n}=1179)$

$\begin{array}{lllll}\text { Agree } & 142(12.0) & 80(56.3) & 62(43.7) & 0.856 \\ \text { Disagree/ Don't know } & 1037(88.0) & 596(57.5) & 441(42.5)\end{array}$

HPV vaccine may encourage people to have multiple sexual partners $(\mathrm{n}=1177)$

$\begin{array}{lcccc}\text { Agree } & 132(11.2) & 80(60.6) & 52(39.4) & 0.456 \\ \text { Disagree/ Don't know } & 1045(88.8) & 596(57.0) & 449(43.0) & \end{array}$

My parents might not allow me to get the HPV vaccine $(\mathrm{n}=$ 1180) Agree
$184(15.4)$
$81(44.0)$
$103(56.0)$
0.000
Reference 
My religion prohibits me from

receiving HPV vaccine because

it is sexual related $(\mathrm{n}=1180)$

$\begin{array}{lllll}\text { Agree } & 101(8.6) & 64(63.4) & 37(36.6) & 0.208 \\ \text { Disagree/ Don't know } & 1079(91.4) & 612(56.7) & 467(43.3)\end{array}$

${ }^{7}$ Responses less than total number who had heard of HPV or HPV vaccination $(n=1209)$ due to lower response rate

${ }^{\dagger}$ Not included in multivariate analysis due to small sample

${ }^{*} p$ value $<0.05, * * p$ value $<0.01, * * * p$ value $<0.001$

Hosmer and Lemeshow test; chi-square:8.087, $p$-value: 0.425, Nagelkerke R square: 0.099 